\title{
VISLUMBRANDO BROTES VERDES: A PROPÓSITO DE 15 VIVIENDAS SOCIALES JUNTO AL SILO DE ALBACETE
}

\author{
María Elia GutiÉRrez Mozo \\ Universidad de Alicante
}

Recibido: $24 / 03 / 2014$

Aceptado: 12/05/2014

\section{Resumen}

Ante la constatación de los cambios que la sociedad española ha experimentado en los últimos cuarenta años y que tienen en el concepto de la familia un reflejo de primer orden, el artículo plantea la relación entre las maneras de vivir (modos de habitar) y las viviendas, muy presente en el debate arquitectónico. Las casas son nuestro mundo, el que construimos, donde se revela tanto nuestra forma de ser como nuestra forma de entender, de estar y de actuar en el mundo. Para ilustrar esas relaciones, se efectúa un breve repaso por algunos de sus hitos: la Villa Rotonda, el Hôtel Tassel y la doble vivienda de Le Corbusier en la Weissenhofsiedlungen, que nos conduce hasta el estudio de un caso, el de un bloque aislado de 15 viviendas sociales junto al silo de Albacete, obra de la arquitecta Rosana Pérez González.

Palabras clave: Viviendas, modos de habitar, sostenibilidad económica, social y medioambiental, Albacete, Rosana Pérez González

\begin{abstract}
Given the changes that Spanish society has undergone in the last forty years, and how the concept of the family has also evolved, the article discusses the relationship between ways of life (ways of living) and housing - a discussion that is ever-present in contemporary architectural debates. Houses are our world, and they reveal both the way we are as well as our way of understanding, living and acting in the world. To illustrate these relationships, a brief review of some of its landmarks is analysed: the Villa Rotonda, the Hôtel Tassel and the double housing of Le Corbusier in Weissenhofsiedlungen. These discussions will then lead us to the case study, that of an isolated
\end{abstract}


block of 15 social houses next to the Albacete's silo, designed by the architect Rosana Pérez González.

Keywords: Houses, ways of living, economic, social and environmental sustainability, Albacete, Rosana Pérez González. 


\section{Introducción: Como hemos cambiado ${ }^{1}$}

Hace ya un tiempo que en los debates de arquitectura se trae, de forma recurrente, la cuestión de los modos de habitar de la que parece hacerse eco no solo la profesión sino también la sociedad en general (Maneras de vivir ${ }^{2}$ es una popular canción rock de la movida madrileña de los ochenta). Nuestra sociedad posmoderna asume la complejidad y la contradicción (la incertidumbre también) como señas de identidad de las cuales la arquitectura no permanece al margen, antes al contrario, trata de liderar (no en vano posee una innegable capacidad de impacto visual y, a renglón seguido, mediático).

Todo ha cambiado. Más aún: cambia sin parar, sigue cambiando. Vivimos de otra manera porque somos distintos, diferencia que, acaso, es más una creencia que al mercado le interesa subrayar que una realidad. Asumiendo que somos diferentes, habrá que precisar en relación a quiénes. La respuesta suele ser sencilla: distintos de los que nos han precedido; nuestro prurito de significarnos no suele ir más allá. Y, ¿qué o quiénes nos han precedido? Nuestros padres.

Si la edad media del ciudadano español ${ }^{3}$ le sitúa en esa tierra media a la que se refería Lola Huete Machado en El País Semanal del 28 de octubre de 20124, o sea, más o menos en los cuarenta, sus progenitores habrán nacido, aproximadamente, en la década de los 40 y serán, por tanto, hijos de la posguerra civil española. Así que estos padres tuvieron, probablemente, una infancia dura, una adolescencia expectante y una juventud que se miró en el mayo del 68 francés. Conocieron los primeros utilitarios, los primeros electrodomésticos, las primeras píldoras para el control del embarazo. Se casaron jóvenes

1. Como hemos cambiado es el título de una canción pop del grupo Presuntos Implicados, del año 1991, que abría el disco Ser de agua.

2. Maneras de vivir es el título de una canción rock del grupo Leño (Rosendo), del año 1981, que abría el disco del mismo nombre publicado en 1997 como recopilatorio.

3. Ver los datos del Instituto Valenciano de Investigaciones Económicas, Ivie, en su página web: http://www.ivie.es/downloads/2014/03/NP-tablas-mortalidad-Ivie-070314.pdf

4. Huete Machado, Lola. «La tierra media». El País Semanal 1883 (2012), pp. 42-51. 
(desde nuestra perspectiva actual) y nosotros, sus hijos, hemos disfrutado de esa energía en nuestros primeros años de vida.

Cuando cayó el muro de Berlín (9 de noviembre de 1989) ellos tenían unos cincuenta años y nosotros más de veinte. De alguna manera, ellos desde la madurez y nosotros desde la juventud, intuimos que ese hecho era trascendental. Tanto, que hay quien pone en él el final de una era y, obviamente, lo era: la de la guerra fría, la de los bloques, la que daba sentido a las películas del agente 007. Pero el cambio que nos llenaba de mariposas el estómago iría mucho más lejos de lo que entonces podíamos intuir siquiera: sin alternativa en el modelo económico, político y social, el capitalismo más despiadado se ha hecho dueño y señor de todos y de todo.

El nuevo «enemigo» que terminó de dar la vuelta de tuerca al sistema de nuestras libertades y derechos hizo su aparición triunfal en escena el 11 de septiembre de 2001, doce años después de la caída del muro de Berlín, estrellando dos aviones contra las Torres Gemelas de la ciudad de Nueva York. Primero, un hecho político; después, uno bélico y, finalmente, uno económico: la crisis que estalla con la caída de Lehman Brothers (15 de septiembre de 2008). Todo el mundo que conocíamos se ha desvanecido (como los dineros de algunos pequeños ahorradores) o ha reventado roto en mil pedazos.

¿Y las personas? También, inevitablemente, hemos cambiado. Y, con nosotros, la familia y la sociedad. Si recuperamos al aludido español o española medios, nuestro o nuestra cuarentañero o cuarentañera, veremos que, probablemente, sea progenitor de unos hijos preadolescentes, porque los tuvo pasados los treinta. Quizá viva en pareja, o acaso no, dadas las estadísticas de divorcio en nuestro país o, si la crisis lo ha arrollado, es posible que lo encontremos de retorno instalado en la casa de sus padres, ahora abuelos.

Puede que sus hijos (raramente más de dos) lo sean biológicos o puede que sean adoptados, en cuyo caso es fácil que esos niños sean de otros países y de otras etnias. Además, puede que su pareja sea de diferente sexo o del mismo y, si les ha apetecido, en cualquiera de los supuestos han podido casarse gracias a una ley del primer gobierno de Zapatero5. También podría darse la circunstancia de que su pareja no fuera la primera, ni del uno ni del otro, y que hijos de uniones anteriores convivieran juntos.

En fin, basta con mirar alrededor para ver que eso que llamábamos familia (y que algunos catecismos y libros de texto siguen dibujando con un papá, una mamá, un niño y una niña) también se ha transformado, tanto que sería

5. LEY 13/2005, de 1 de julio, por la que se modifica el Código Civil en materia de derecho a contraer matrimonio (BOE $\mathrm{n}^{\circ} 157$ de 2 de julio de 2005). 
más pertinente decir que se ha metamorfoseado. La variedad (donde dicen que está el gusto) es el nuevo tema.

Es tan diferente el panorama, y para algunos tan desconcertante, que empieza a proliferar la nostalgia (ver, al respecto, la cantidad de programas de televisión cuya temática gira en torno a este sentimiento) por un supuesto tiempo pasado ¿mejor?

\section{Maneras de vivir y viviendas}

Como decíamos al principio de este artículo, el gremio de los arquitectos ha acusado recibo muy pronto, al menos en el plano teórico, de toda esa serie de cambios (políticos, sociales, culturales, económicos) que conllevan una manera o, mejor dicho, unas maneras diferentes de vivir. Por ejemplo, el Colegio Territorial de Arquitectos de Valencia montó en 1995 un curso titulado Nuevos Modos de Habitar en el que participaron 28 conferenciantes que reflexionaban sobre «estrategias con las que romper la rígida estructura del entorno doméstico, reconsiderando los estereotipos asumidos y las actitudes que estos conllevan, intentando un proyecto contemporáneo de vivienda $»^{6}$. Entre ellos, se hallaban algunos tan prestigiosos como Alberto Campo Baeza, Manuel Gallego, Vittorio Gregotti o Kenneth Frampton, y tan solo dos mujeres: Monique Eleb y María José Aranguren, aunque otras dos estuvieron al frente de la coordinación del curso (María Melgarejo) y de la consiguiente publicación (cuando hoy, casi veinte años después, vemos esto nos damos cuenta de que, despacio, sí, pero ¡cuánto han cambiado las cosas!).

La primera cuestión que salta a la vista es la inmediata relación, por íntima y natural, entre las maneras de vivir y las casas. Nuevos modos de habitar implican, en primerísimo lugar, nuevas maneras de entender, proyectar, hacer y usar las viviendas. La ciudad también, pero esa reflexión viene después, a continuación, como el tejido resultante de esa célula habitacional que es la casa. Así, la conferencia de Vicente Vidal en el citado evento se titulaba «La célula de habitación como configuradora $»^{7}$ y Manuel Gallego en su aportación al mismo dice:

Me estoy refiriendo a la célula mínima del espacio de uso cotidiano, al espacio de la vida privada, e intento indagar qué relaciones mantiene el hombre con ese espacio: casa, lugar, residencia. Cómo ese hábitat-vivienda se liga a su vida y cómo sus cambios son cambios de la actitud del hombre. Cómo ese

6. Planelles, Mercedes (coord.). Nuevos modos de habitar. New ways of housing. Valencia, Colegio Oficial de Arquitectos de la Comunidad Valenciana, 1996, en la solapa de la portada.

7. Planelles, Mercedes. Op. cit., p. 151.

Feminismo/s 23, junio 2014, pp. 227-250 
espacio se personaliza, se va haciendo de uno frente al espacio de los otros y cómo el hombre construye su mundo en él. Se puede entender como un lugar donde construye su vida.

La casa es el tema por excelencia de la arquitectura, no sólo cuantitativamente, lo cual es obvio, sino cualitativamente. Como la historia de la arquitectura apenas había reparado en ellas, excepción hecha de sus manifestaciones áulicas, y como el Movimiento Moderno se postula precisamente como anti-histórico, a él debemos la reivindicación del tema de la casa como el tema de la arquitectura.

El profesor Laborda Yneva, en su Enseñar arquitectura. Lecciones de composición arquitectónica, en el capítulo que dedica a la casa, dice:

Y si la casa es el paradigma de la arquitectura, el habitar lo es también con relación a la condición inteligente del hombre. La forma de habitar y sus consecuencias dimanan del instinto dominado, seguramente el acto más humano de cuantos cabe ejercer. Todavía está por venir la respuesta a la pregunta constante sobre la inmanencia de la casa, de ahí su extraordinario atractivo. No es la condición humana la que habita en ella, es la gente, semejante pero distinta. Podríamos incluso recordar a Alberti: Nada diferencia tanto al hombre del hombre como su capacidad para comprender lo bello ${ }^{9}$.

Para el citado profesor, la arquitectura es, sencillamente, «una manera de afrontar las cosas» cuyas «dos categorías esenciales» son «la evocación y el cobijo», las cuales responden, respectivamente, a «sendos estímulos instintivos que subyacen bajo la precariedad de su presencia en el mundo: la incertidumbre ante lo desconocido (símbolo) y la incertidumbre ante el entorno próximo (función)» ${ }^{10}$.

Una de las obras que más impacto ha tenido entre estudiosos y estudiantes de Arquitectura es el libro de Iñaki Ábalos La buena vida. Visita guiada a las casas de la modernidad ${ }^{11}$ donde propone visitar siete casas del siglo XX en siete jornadas o capítulos, en un recorrido que niega la modernidad como experiencia triunfante del positivismo y recupera la pluralidad del siglo. Su objetivo es alertar y contribuir a una mayor conciencia de los vínculos entre las formas de pensar, de ver el mundo, los modos de vida y las técnicas proyectuales, las cuales no son neutrales sino que limitan y contienen en sí mismas la capacidad crítica de nuestro trabajo. Es decir, pone en relación una serie de

8. Planelles, Mercedes. Op. cit., p. 169.

9. LABORDA YNEVA, José. Enseñar arquitectura: lecciones de composición arquitectónica. Zaragoza, Institución Fernando el Católico, 2008, pp. 61-62.

10. LABORDA YNEVA, José. Op. cit., pp. 61-62.

11. ÁBALOS, Iñaki. La buena vida: visita guiada a las casas de la modernidad. Barcelona, Gustavo Gili, 2001. 
casas modernas con las formas de habitarlas y con sus propios habitantes, a la vez que revisa y remueve algunos de los supuestos más firmemente arraigados sobre la Modernidad.

Hasta aquí hemos visto cómo ha cambiado la sociedad, la familia, las personas en el último cuarto de siglo, veinticinco años en los que la revolución de las tecnologías de la información y la comunicación es una realidad y la era digital una presencia cotidiana en nuestras vidas. Hemos repasado asimismo cómo la vivienda es, por un lado, el paradigma de la arquitectura y, por otro, el termómetro que más y mejor registra esas transformaciones en la manera de ser, estar y pensar el mundo por cuanto ella misma es un mundo, nuestro mundo, el mundo que nos construimos. Veamos ahora cómo interaccionan las casas y los modos de vida.

\section{Casos y casas}

Tomemos tres ejemplos, separados en el espacio y en el tiempo, para ilustrar las relaciones entre las maneras de vivir y las viviendas. Se han elegido por su elevada capacidad para representar las formas de vida más avanzadas en tres épocas diferentes y sucesivas: el Renacimiento, que parte de la tradición clásica no para remedarla sino para superarla desde la primacía que otorga la perspectiva histórica; el Modernismo, que busca y halla solo en el estilo una auténtica primavera de las artes; y la Modernidad, que, de espaldas al estilo y a la historia, intenta y logra refundar la disciplina desde sus bases técnicas (la máquina), funcionales (de habitar) y formales (la abstracción: L'Esprit Nouveau).

El primero que proponemos es la Villa Rotonda (1567-1570) en Vicenza de Andrea Palladio. Además de su posición en un entorno privilegiado (tanto, que la casa mira a los cuatro puntos cardinales con idénticos pórtico

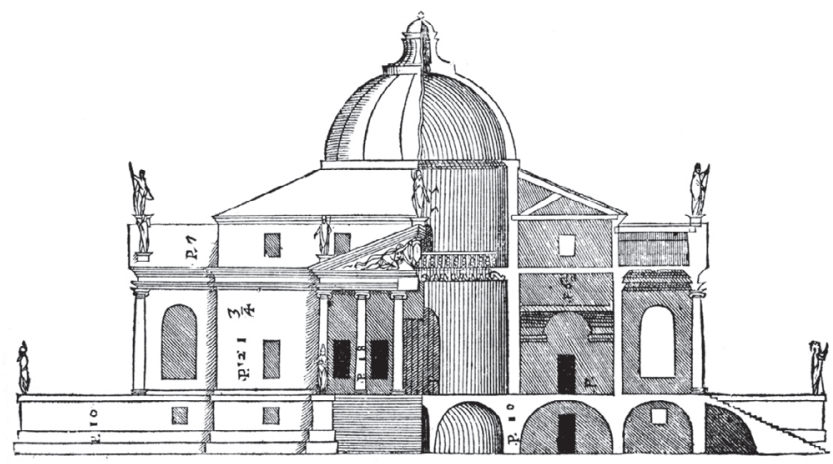

1. Andrea Palladio: Villa Rotonda, Vicenza, 1567-1570. Alzado sección.

Feminismo/s 23, junio 2014, pp. 227-250 
y escalinata), lo que más llama la atención de la Rotonda es que sea una casa, pues no lo parece en absoluto. Elevada sobre un piano terra y culminada con una imponente cúpula, se hace difícil imaginar la vida cotidiana en ella. Y es que, en ella, la vida era una fiesta. Su propietario, Paolo Almerico, vicario apostólico retirado, la mandó construir precisamente como lugar de recreo y esparcimiento en el que celebrar la vida social y poner en escena los atributos de cada cual. Por eso la casa es más bien una extraordinaria tramoya al servicio de una función en la que las personas se convierten, jugando cada una el papel que les corresponde, en personajes.

Bien, pero, ¿dónde se prepara la intendencia de tamaños eventos? En el underground, en el piano terra que no solo la toca sino que nos pone los pies en ella. Cocinas, almacenes, servicios, etc., se alojan en este nivel inferior. En este caso, no son pertinentes los versos de Calderón:

Hermosa compostura

De esta inferior y varia arquitectura

Que, entre sombras y de lejos,

A la celeste usurpas los reflejos ${ }^{12}$.

Pues la arquitectura inferior no es reflejo, si quiera pálido, de la celeste (la cual cubre una cúpula), sino su sustento y fundamento: la vida cotidiana tiene lugar en ella y prepara los fastos de la vida social, función teatral por excelencia en un escenario digno del anfitrión.

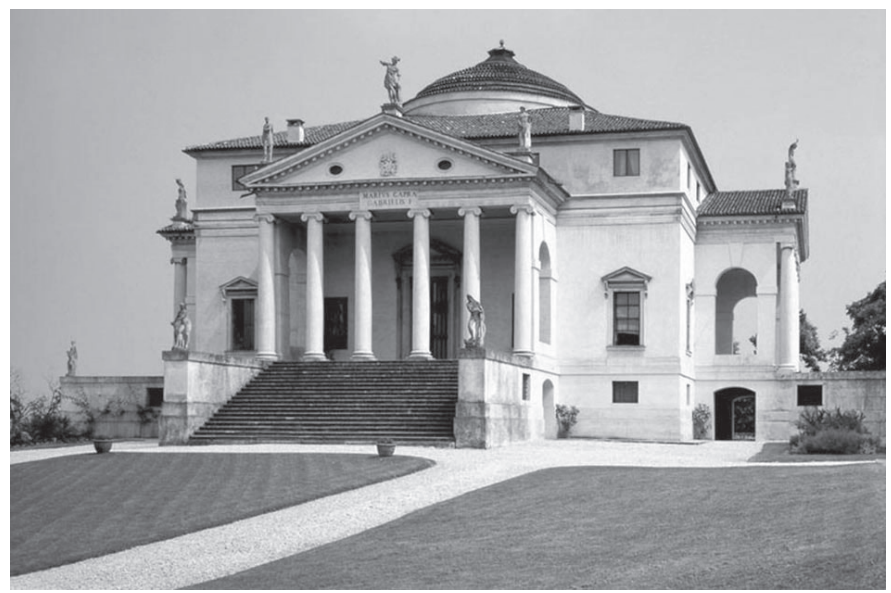

2. Andrea PALladio: Villa Rotonda, Vicenza, 1567-1570. Vista exterior.

12. Calderón de La BarCa, Pedro (1600-1681). El gran teatro del mundo. Barcelona, Crítica, 1997. 


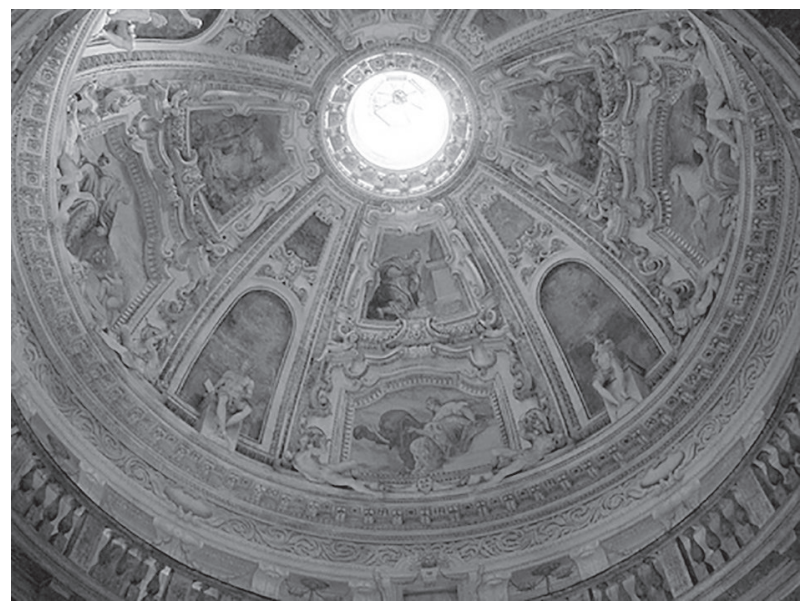

3. Andrea Palladio: Villa Rotonda, Vicenza, 1567-1570. Vista interior cúpula.

El segundo caso que traemos para su comentario es el Hôtel Tassel de Victor Horta en Bruselas (1892-1893). Ahora nos encontramos en un entorno urbano, frente al campestre anterior, y con una parcela característica entre medianeras. La fachada, relativamente breve, ha de apurar las posibilidades de representación del propietario de la casa (un profesor de geometría soltero que vivía con su abuela $)^{13}$ y se entrega a fondo en el empeño, consiguiendo el tesoro más preciado en una sociedad burguesa: la singularidad. En el Modernismo, y como explica magistralmente el profesor Urrutia ${ }^{14}$, la casa es la joya

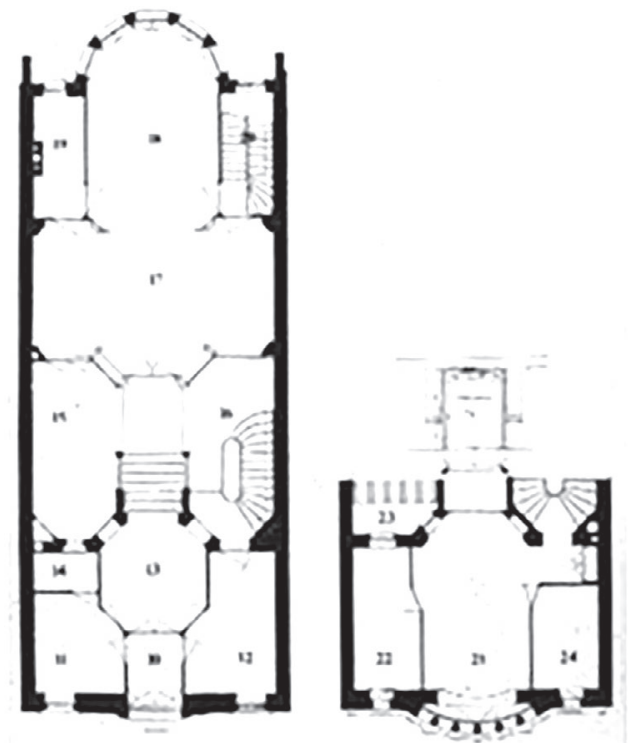

4. Victor HORTA: Hôtel Tassel, Bruselas, 18921893. Plantas niveles inferiores.

13. BORSI, Franco y PORTOGHESI, Paolo. Victor Horta. Bruselas, Marc Vokaer, 1970.

14. URRUTIA NúÑEZ, Ángel. Arquitectura española, siglo XX. Madrid, Cátedra, 1997, pp. $39-47$. 


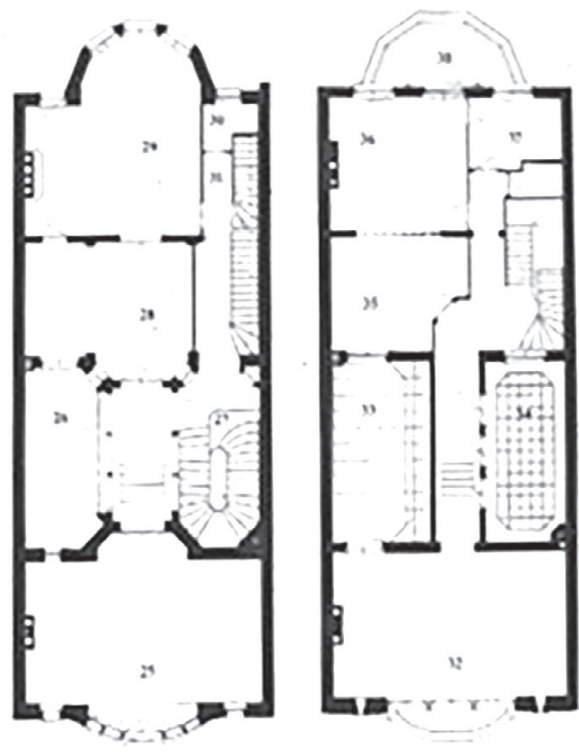

5. Victor HoRTA: Hôtel Tassel, Bruselas, 18921893. Plantas niveles superiores.

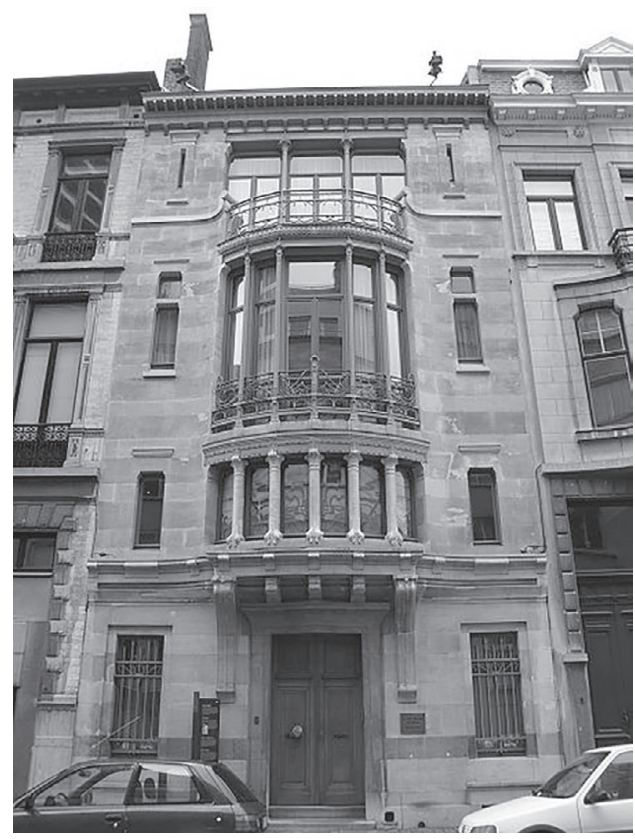

6. Victor HORTA: Hôtel Tassel, Bruselas, 18921893. Vista exterior. engastada en el tejido urbano. Lo más importante es que simbolice no la función (eso fue asunto de los arquitectos visionarios del XVIII ilustrado) sino la propiedad, por eso esta casa tiene el nombre de su dueño. Todo encaja como anillo al dedo: la domus (la casa) precede y hace al dominus (al señor).

Un señor que desea que su casa lo represente (hemos hablado de la fachada, pero no olvidemos el increíble vestíbulo y la escalera que en él se derrama), pero, y esto es muy importante, que sea asimismo confortable, para lo cual los oficios desempeñarán un papel protagonista: el que provee el lujo.

Para la consecución de esa comodidad y habida cuenta de que su generoso programa ha de distribuirse en diferentes niveles, la casa se organiza con las llamadas zonas de día en el primero, reserva el segundo para las de noche y aloja al servicio en la última. En las residencias decimonónicas y urbanas, las diferentes alturas manifiestan explícitamente las jerarquías y, así, los señores se instalan en la planta noble y el resto de inquilinos y el servicio en las plantas superiores a las que hay que acceder por escaleras, escaleras que, a su vez, se duplican para el 
uso de unos y otros. El ascensor, evidentemente, le dará la vuelta a este esquema.

El tercer ejemplo que deseamos comentar es la doble casa que Le Corbusier construye para la Exposición del Deutscher Werkbund, en Stuttgart, en 1927, en la Weissenhofsiedlungen. Nos hallamos ahora en pleno siglo XX y en plena euforia de la Modernidad de la cual, por encima de cualquier otra solicitación, esta casa se erige en manifiesto construido. Le Corbusier había postulado en 1926 sus cinco principios para una nueva arquitectura, a saber: elevar la casa sobre pilotis para «mancillar» el suelo lo menos posible, para posarse sobre la

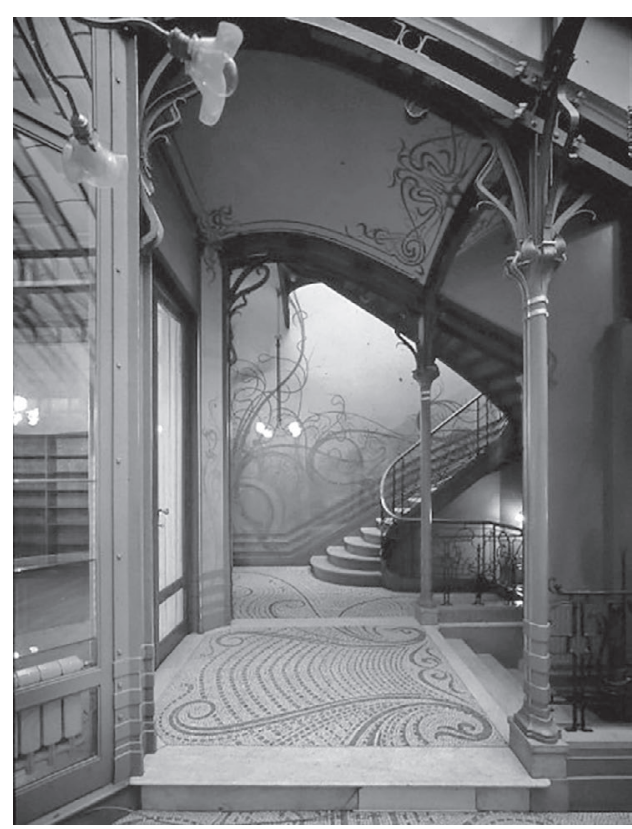

7. Victor HORTA: Hôtel Tassel, Bruselas, 18921893. Vista interior escalera y hall. naturaleza sin apenas tocarla; la planta libre, es decir, libremente distribuida gracias a que las particiones se ven liberadas de misión portante al recaer ésta enteramente sobre la estructura; fachada libre, consecuencia asimismo de la independencia de estructura y cerramientos (esqueleto y piel); la ventana alargada, panorámica, más y mejor adaptada a la visión humana y asimismo posible en virtud del divorcio entre estructura y cerramientos; y la terraza jardín, donde se le devuelve a la naturaleza lo que la huella de la edificación sobre la misma le ha usurpado y donde se dan cita las alegrías esenciales que tanto preocupaban al maestro: sol, espacio, verdor.

Pero, además, el modelo de Stuttgart es un prototipo, es decir, una idea pensada para su construcción industrializada y seriada, producto de la aspiración a hacer de la casa un artefacto con la misma precisión y la misma eficacia que, por ejemplo, un automóvil. La casa, pues, como máquina de habitar que se dimensiona con parámetros de optimización económica inspirados en las medidas de los elementos de los vagones de un tren, donde los dormitorios son cabinas que, durante el día, borran sus límites para convertirse en sala de estar y, por la noche, se compartimentan. 


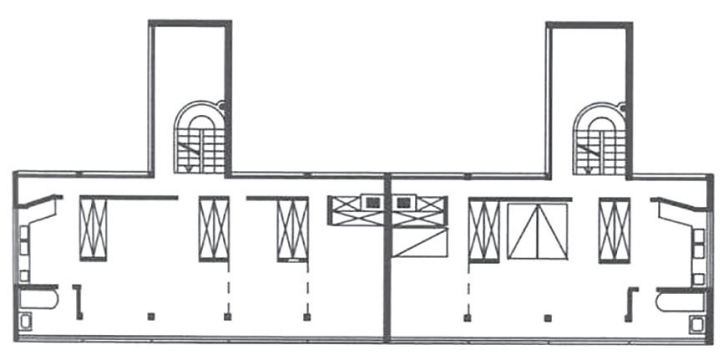

8. Le Corbusier: Casa doble en la Weissenhofsiedlungen, Stuttgart, 1926-1927. Planta.

¿Qué vida podemos imaginar en esta casa? Sin duda, complicada, entre otras cosas porque los tamaños que se soportan en el coche cama de un tren, esto es, durante un viaje, difícilmente se sobrellevan en la vida cotidiana, por no hablar sobre la cuestionable intimidad de las habitaciones (las separa un panel deslizante) o de los espacios servidores, como cocina y baño. Quizá la clave esté en poner el acento en la definición de la casa como máquina y relegar a un segundo plano que su función es la de habitar. O acaso en entender que es un prototipo y no un modelo, el cual, además, de alguna manera

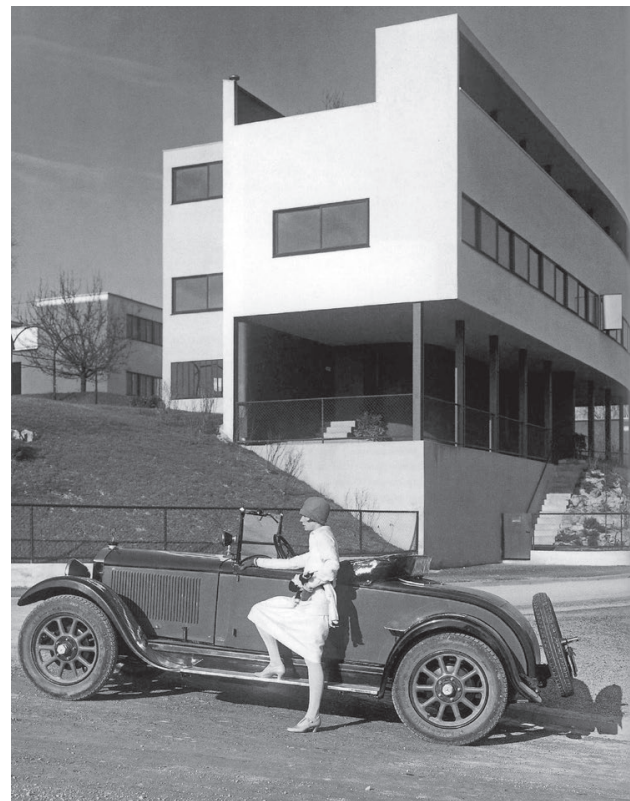

9. Le CoRbusier: Casa doble en la Weissenhofsiedlungen, Stuttgart, 1926-1927. Vista exterior. tiene que llamar la atención en una colina de casas blancas que salpican la ladera de una exposición donde el comisario, Mies van der Rohe, se ha ocupado muy mucho de repartir las parcelas y, en el reparto, quedarse con la mejor parte (el bloque que preside el conjunto).

Es inevitable pensar en esa secuencia de la película de Charlot, Tiempos Modernos (director Charles Chaplin, 1936), donde el pobre obrero que pasa su interminable jornada laboral ajustando tuercas, cuando la termina, no puede dejar de hacer el mismo gesto, convirtiéndose él mismo en un autómata. $Y$ es que, si bien es verdad que el hábito no hace al monje y 
que la habitación no hace al habitante, no lo es menos que la arquitectura y sus disposiciones nos predisponen para hacer las cosas de una manera u otra. Acaso el habitante de la doble casa de Le Corbusier sea este entrañable personaje, capaz de hacer de ella un hogar después de haber pasado por el hospital, la cárcel y la calle.

Hemos repasado, a vuela pluma, algunos de los hitos domésticos de la historia de la arquitectura para ilustrar la relación existente entre las casas y los modos de vida y de habitarlas. Vayamos ahora al objeto (luminoso) de nuestro deseo: unas casas del siglo XXI.

\section{Las 15 viviendas de Rosana Pérez González en Albacete}

En un lugar que pelea por serlo, allí donde la ciudad muestra abiertas las heridas de viejas infraestructuras como el antiguo paso del ferrocarril, convertido en Paseo de la Cuba después de trasladarlo en los años sesenta del pasado siglo, donde equipamientos soberbios, como el Silo de la Red Nacional, exhiben una encomiable dignidad a pesar del maltrato y del olvido, donde el tejido urbano está roto y deshilachado por su condición limítrofe con el Polígono Industrial Campollano y las muchas vías que acometen y circunvalan la ciudad, donde las calles aún no tienen nombre (Sector I, Unidad de Ejecución 5, parcela M-2), allí precisamente es donde la arquitecta Rosana Pérez González, albaceteña titulada por la Universidad de Alicante, ha proyectado y construido un edificio de 15 viviendas protegidas con garaje y trasteros, y local comercial, para la empresa Comuñas \& Artemio acabado el año pasado, en 2013.

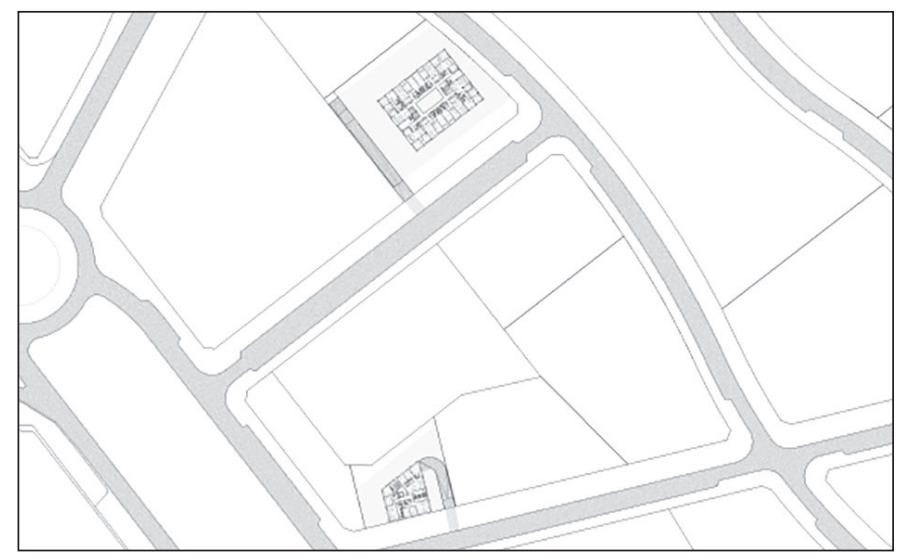

10. Rosana Pérez González: Edificio en bloque aislado de 15 viviendas, Albacete, 2013. Plano de situación. 
La parcela tiene forma irregular y la edificación se ajusta a ella, trapecial. Sus lados están casi orientados a los cuatro puntos cardinales. Cada una de sus cinco plantas de pisos alberga tres viviendas, dos de dos dormitorios (sencillo y doble) y una de tres (dos sencillos y uno doble), todas con aseo (y ducha) y cuarto de baño (y, por tanto, bañera). No hay patios, todo (a excepción de aseos y baños) vuelca a fachada, incluida la escalera, que mira al norte, así que la luz inunda las estancias para apurar la cual y habida cuenta de la justeza de las dimensiones de las piezas habitables, los huecos son ventanas balcón que se rasgan casi de suelo a techo y se dividen en dos partes de las cuales sólo la superior es practicable y, para evitar particiones en la carpintería y por calidad de la misma, abatible. La arquitecta dibuja cuidadosa y primorosamente ese abatimiento en todas y cada una de las habitaciones para mostrar la no injerencia en el buen funcionamiento de las mismas. También se dibuja, con el mismo espíritu, el nicho que albergará los radiadores: todo pensado, todo dibujado, cada cosa en su sitio y un sitio para cada cosa. Un orden resplandeciente que, lejos de encorsetar la vida, le procura (Valéry) la mayor libertad.
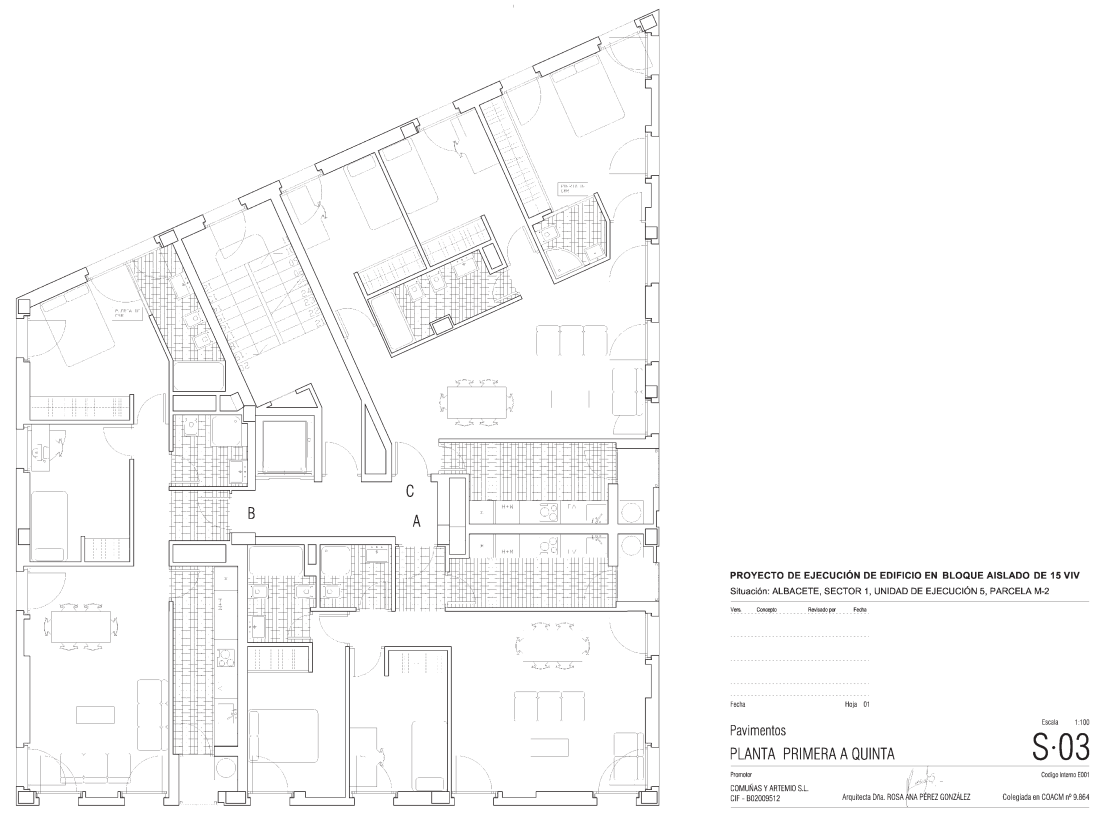

11. Rosana PÉREZ GonZÁlez: Edificio en bloque aislado de 15 viviendas, Albacete, 2013. Planta de pavimentos. 
Dos de las salas de estar-comedor se disponen en esquina, situación privilegiada en su condición de atalaya: una en la sureste y otra en la suroeste. La tercera abre al este, al sol naciente. Las cocinas presentan el esquema bancada y paso, es decir, sirven estrictamente para el trabajo que en ellas se desarrolla y se completan con una terracita tendedero que desahoga la vivienda y aloja las calderas. En fachada se significan por una celosía y porque el hueco lo es, ahora sí, libre de cajas de persiana que instalar, de suelo a techo.

Inevitable preguntarse por qué, adyacentes como lo son, las cocinas no abren al salón-comedor, esponjando unos espacios que lo hubieran agradecido en ambos casos y permitiendo incorporar la vida de una y otra estancias, y, con ella, probablemente, las tareas y labores que acogen ${ }^{15}$. Quizá ese modo de vida que, en algunos lugares como Albacete, aún se llama «americano» no está todavía asumido y sea un hándicap para que el promotor pueda vender estas viviendas; sin embargo, podría haberse ofertado como propuesta inicial y, luego, quien deseara compartimentar, que lo hiciese.

Baños, cocinas y vestíbulos se aglutinan en bandas que el propio plano de pavimentos subraya. En este sentido (y en otros: es lo más cuestionable del proyecto, acaso porque no cabía ese tercer dormitorio metido con calzador y porque la vivienda asume la irregularidad de la parcela habiendo perdido la ocasión de que fuera la escalera, de suyo un espacio irregular, quien lo hiciera), la vivienda mayor es la menos afortunada: su entrada abre directamente al salón y sus cuartos húmedos forman paquetes discontinuos. La autora del proyecto trata de «compensar» estos inconvenientes haciendo un poquito mayor la cocina y disponiendo el dormitorio principal en la esquina nordeste. Todos los dormitorios, los de esta vivienda y los demás, poseen espacio de almacenamiento generoso en forma de armario empotrado, elemento ya defendido por Loos como signo inequívoco de modernidad frente a los aparatosos muebles modernistas ${ }^{16}$.

La vivienda tipo A recae al sur con esquina al este; la tipo B al oeste, con dos esquinas: al sur y al norte (su dormitorio principal también «chirría» por obedecer a la escalera), y la tipo C, en forma de afilada cuña, al norte y al este. La estructura dispone pilares en las fachadas y en sus paralelas norte y sur.

Este edificio se proyectó junto a otro de 56 viviendas, en construcción, cuyos autores son COR \& Asociados. Conviene aclarar que, en la memoria de los proyectos, a disposición en la página web de la firma, las afirmaciones que

15. BRaVo BRAVO, Juan. «Así en la cocina como en la fábrica». Feminismo/s 17 (2011), pp. 183-211.

16. Loos, Adolf. «La abolición de los muebles», en Ornamento y delito y otros escritos, Barcelona, Gustavo Gili, 1972, pp. 159-160. 

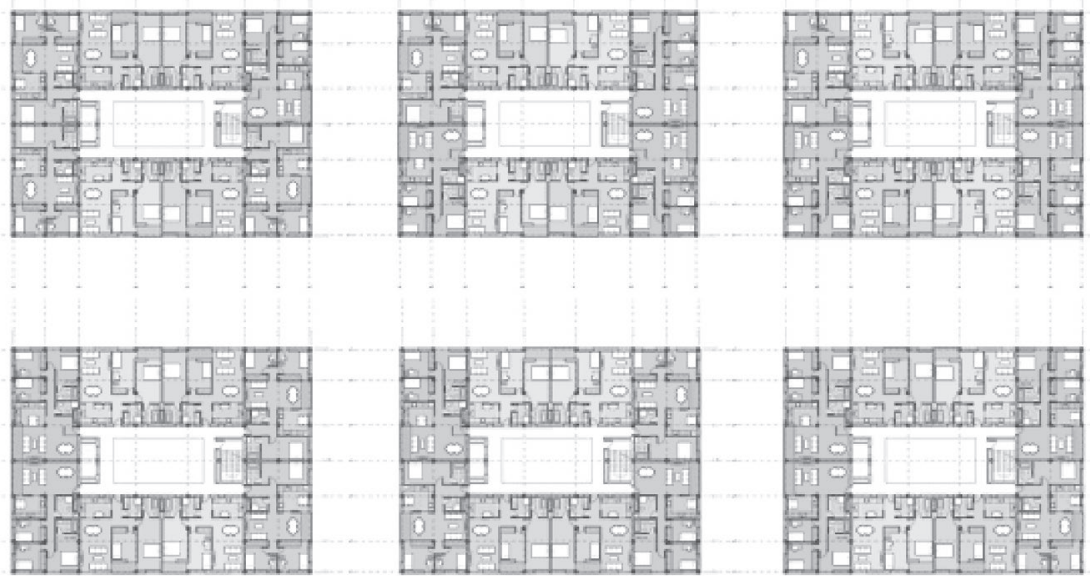

12. Miguel Rodenas y Jesús Olivares: Edificio en bloque aislado de 56 viviendas protegidas con garaje y trasteros, y local comercial, Albacete. Plantas.

se vierten son más pertinentes en el caso de las 56 viviendas que en el de las 15, quizá porque las dimensiones de la parcela lo permiten y, así, se nos dice:

Ambos coinciden en el tiempo, y en un contexto de redimensionamiento del sector inmobiliario en España (2009-2010), iniciado tras la crisis económica. El diseño, por tanto, se produce en el momento de mayor incertidumbre del devenir económico, donde la actividad promotora no disfruta de las mismas garantías, ni los clientes de los mismos recursos ${ }^{17}$.

Estamos, pues, en un caso de clara adaptación a las circunstancias que, lejos de percibirse como limitación, se reciben como reto y oportunidad para repensar la disciplina. Así, se nos informa de que:

Los parámetros de proyecto de los edificios han tenido como referencia constante la medición económica de los siguientes conceptos:

1.- La consigna de que el usuario final debe invertir los mínimos esfuerzos en aclimatar los espacios, con la consiguiente reducción en la tarifación energética futura. Todas las estancias habitables dan a exterior; todas las viviendas poseen ventilación cruzada; y todos los recorridos de los conductos de instalación son mínimos y centralizados, con la consiguiente reducción de las pérdidas de $\operatorname{carga}^{18}$.

17. < http://www.cor.cc/proyectos.php? $\mathrm{p}=45 \& \mathrm{l}=1 \& \mathrm{o}=3>$, consultado el 13-08-2013 18. < http://www.cor.cc/proyectos.php? $\mathrm{p}=45 \& \mathrm{l}=1 \& \mathrm{o}=3>$, consultado el 13-08-2013 
Nos hallamos, por tanto, ante unos edificios energéticamente eficientes que lo son, además, sin recurrir a más mecanismos que un diseño racional y razonable, en el cual lo importante es la orientación de las viviendas y su distribución (la ventilación cruzada solo es posible en las 56; en las 15, no).

2.- El comprador destina la menor cantidad de dinero posible a la compra de metros cuadrados útiles en espacios servidores (pasillos, hall de acceso, pasillos de planta). Manteniendo la misma calidad en amplitud de espacios, los clientes ahorran entre 10.000-20.000 € de inversión. También se potencia la inversión en materiales aislantes, carpinterías e instalaciones, ahorrando en revestimientos, cuya variedad y precio dada la coyuntura económica es cuantiosa y óptima ${ }^{19}$.

En este indicador se mide tanto la proporción que representan los espacios servidores frente a los servidos (la cual trata de minimizarse) como la calidad de los materiales en los cuales va a recaer el peso para hacer frente al ahorro de consumo energético, lo que representa una apuesta clara por la durabilidad, parámetro fundamental de una cultura del mantenimiento y la conservación, es decir, de la sostenibilidad.

Conviene destacar, y elogiar, esta decisión técnica que prefiere aportar recursos económicos en aquello que no se ve (aislamientos, instalaciones), pero que contribuye activa y positivamente al confort ambiental, en vez de gastarlos en revestimientos. Es, por así decirlo, un proyecto silencioso: su procesión, que la hay, va por dentro ${ }^{20}$.

3.- La relación entre metros cuadrados construidos y útiles será la más cercana a 1, con lo que el promotor garantiza en parte la viabilidad de su negocio, al estar el precio de venta tasado por la administración. Esto no es suficiente con sólo plantearlo, y se ha llevado a efecto de forma radical. Los volúmenes son compactos, ocupando el mínimo de parcela posible. La estructura se dispone entre el perímetro de fachada y los núcleos de comunicación vertical, para dejar libre la superficie de vivienda. La ubicación de los huecos de instalaciones permite la redistribución de las estancias según el criterio o circunstancias venideras de los inquilinos.

En cuanto al diseño los espacios son neutros con la intención de que sea el cliente quién termine de personalizarlos ${ }^{21}$.

No sólo se minimiza la repercusión de las zonas servidoras frente a las servidas, también se lleva casi a la unidad la relación entre la superficie útil y la construida, de la que deriva, por añadidura, una distribución mínimamente

19. < http://www.cor.cc/proyectos.php? $\mathrm{p}=45 \& \mathrm{l}=1$ \&o=3>, consultado el 13-08-2013

20. TUSQUETS, Óscar. Dios lo ve. Barcelona, Anagrama, 2001.

21. < http://www.cor.cc/proyectos.php? $\mathrm{p}=45 \& \mathrm{l}=1$ \&o=3>, consultado el 13-08-2013

Feminismo/s 23, junio 2014, pp. 227-250 
fragmentada capaz de adaptarse y acoger mil y una formas de vida. Es justamente la flexibilidad en el uso la que hace tan funcional la vivienda, de manera que ésta pueda acompañar los cambios a lo largo y ancho de la vida de sus habitantes. Esta cualidad, que lo es resplandeciente en el proyecto de las 56, es menos clara en las 15.

4.- La exigencia de dirigir el producto a los nuevos modelos de familia, midiendo la relación y la privacidad de los espacios. Se promueven múltiples tipologías que equivalen a la variada demanda requerida por parte de jóvenes, familias monoparentales, familias tradicionales, solteros, parejas de mayor $\operatorname{edad} . .22$

Si nuestra sociedad es compleja y la familia presenta fórmulas hasta ahora desconocidas, lo lógico es que las casas que van a habitar presenten y representen esa diversidad, acogiéndola con la misma naturalidad que se produce y haciendo de ella un factor de enriquecimiento del proyecto. El tema es uno: habitar. Y, las variaciones (los habitantes), casi infinitas.

5.- La densificación del barrio. Se proponen un mayor número de viviendas cuyo tamaño será predominantemente menor al que se venía ofertando en la zona. Con esto se pretende rentabilizar el uso de los espacios de esparcimiento y de equipamientos, así como aumentar el potencial número de consumidores de los pequeños comercios, que a su vez crean riqueza urbana ${ }^{23}$.

En esta inquietud podemos leer esa vocación de toda casa de ser tanto una ciudad en miniatura (la civitas minima albertiana) como célula del tejido urbano. Si bien la ciudad actual parte de este segundo supuesto, como nos recuerda el profesor Arnau en sus 72 voces para un diccionario de arquitectura teórica ${ }^{24}$, dado que se planifica del todo a las partes, no es menos cierto que toda casa que lo es posee una irrenunciable vocación cívica, como la que evidencia hacerse más pequeña para que quepan más y salgan las cuentas de lo público, que, por serlo de todos, importa más. Se echa de menos llevar la intención hasta sus últimas consecuencias y haber dispuesto viviendas (y no más locales comerciales) en la planta baja.

6.- Ejecutar las fases conforme a una selección de la demanda real (más que producir una oferta imaginaria o especulativa).

El servicio prestado por la consultoría se ha centrado más en asesorar al cliente en el cambio de producto que en la resolución arquitectónica basada en arquetipos. Entendemos que la productividad y el peso en el PIB

22. < http://www.cor.cc/proyectos.php? $\mathrm{p}=45 \& \mathrm{l}=1 \& \mathrm{o}=3>$, consultado el 13-08-2013

23. < http://www.cor.cc/proyectos.php? $\mathrm{p}=45 \& \mathrm{l}=1 \& \mathrm{o}=3>$, consultado el 13-08-2013

24. ARnAU AMO, Joaquín. 72 voces para un diccionario de arquitectura teórica. Madrid, Celeste, 2000, pp. 20-27. 
del sector de la construcción residencial, han de ajustarse a parámetros de excelencia basados en la gestión del conocimiento geográfico, demográfico y antropológico 25 .

La consecuencia de esta nueva forma de entender el ejercicio profesional es clara en el caso que nos ocupa: las obras de las 15 viviendas están acabadas; las de las 56 en proceso. Del propio relato de los autores de los proyectos, se desprende un entendimiento lleno de sentido común de la tan traída y llevada (y manoseada y manipulada) sostenibilidad, en todos y cada uno de sus componentes. Es muy evidente la preocupación, en plena crisis (túnel del que no se ve salida), económica, que, como una especie de mantra, recorre todo el discurso de los arquitectos. Una economía que, como toda buena regla de la casa (ese es el significado etimológico de la palabra), ahorra en lo adjetivo e invierte en lo sustantivo, pese a quien pese. Una economía que minimiza tabiques y pasos y pasillos y maximiza los espacios para la vida, tanto la privada e íntima, como la pública y social, caras ambas de la misma moneda de nuestra humanidad.

También se nos habla de sostenibilidad medioambiental, dado que la eficiencia energética representa no solo ahorro económico sino, sobre todo, disposición prudente y responsable de los esquilmados recursos del planeta. Y así, estas viviendas sacan partido de lo que se nos da y no cuesta, de la luz, del espacio, de las vistas...

Y es asimismo patente el compromiso con la sostenibilidad social: una arquitectura inclusiva e integradora, donde todos los casos encuentren su casa, donde todas las situaciones hallen acomodo, donde tan importante es que mi vivienda esté bien como que mi barrio funcione porque funcionan sus tiendas, sus equipamientos y sus dotaciones y, con ellos, mi ciudad.

\section{A modo de conclusión abierta o inconclusión}

Podría pensarse que todas estas cuestiones han pasado factura al proyecto y a la obra, que todas estas economías y toda la ecología (la lógica de la casa si seguimos de nuevo el rastro etimológico) que proclaman y observan lo han sido en detrimento de la estética. Nada más lejos de la realidad, en nuestra opinión.

El edificio tiene, y como tal lo trata, un hermano mayor: el magnífico silo que, afortunadamente, no ha sido demolido a pesar de los intentos de acoso y derribo. Un hermano mayor es siempre una referencia y, así, nuestro ejemplar, se erige con una altura semejante, una compacidad similar, una composición

25. < http://www.cor.cc/proyectos.php?p=45\&l=1\&o=3>, consultado el 13-08-2013 


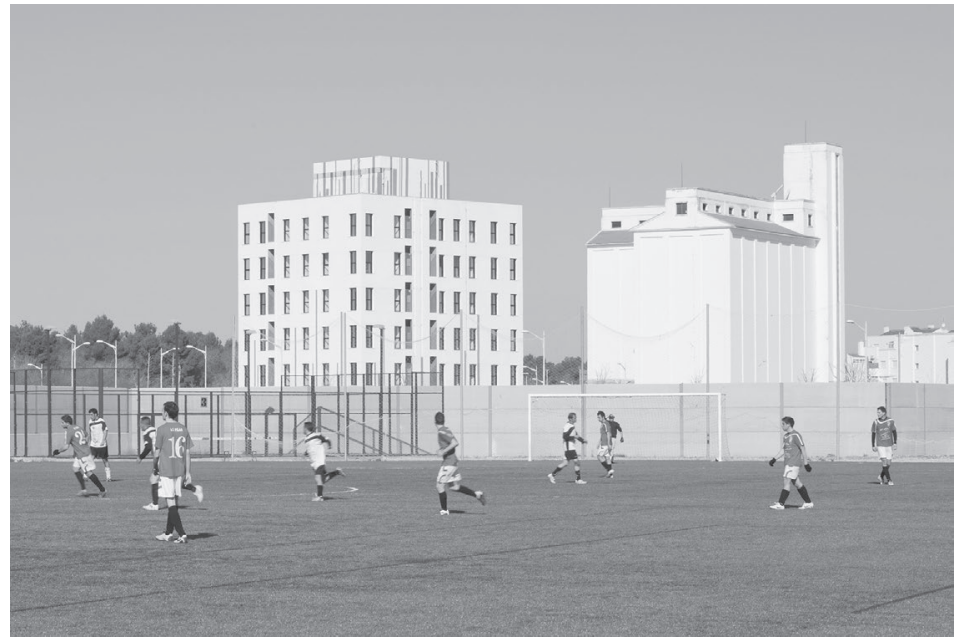

13. Rosana PÉREZ GONZÁLEZ: Edificio en bloque aislado de 15 viviendas, Albacete, 2013. Vista exterior junto al silo.

donde asimismo prima la vertical (recordemos los huecos resueltos como ventanas balcón) y un color blanco roto por el que se encaraman, como las espigas del trigo, unas franjas verdes que, en el casetón que corona la cubierta, descienden como una planta de helecho que sobreabundara su maceta.

Una de las señas de identidad de nuestra políticamente correcta cultura posmoderna, y que afecta especialmente a la diversidad en que se concreta hoy el concepto de familia, es la tolerancia, un término tibio que alude a lo que se permite o, en el mejor de los casos, se respeta pero sin empatizar con ello. Las viviendas de Rosana Pérez González no son tolerantes: son inclusivas. No solo porque eliminan barreras (arquitectónicas y sociales), sino porque la pluralidad, la variedad, el mestizaje, son bienvenidos como parte integrante de un proyecto, no de arquitectura (condición necesaria, pero insuficiente), sino de vida. Son viviendas que, lejos de ofrecer resistencia a la manipulación por parte de sus moradores, invitan a tomar posesión de ellas siendo poseídas por ellos.

Es una arquitectura profundamente amable: como nos dice el DRAE ${ }^{26}$ «digna de ser amada» y «afable, complaciente, afectuosa». Es amable porque es cívica (respetuosa con su entorno y con sus preexistencias y activa en la construcción de una identidad en un retazo de ciudad) y porque es educada

26. <http://lema.rae.es/drae/>, consultado el 07-02-2014 


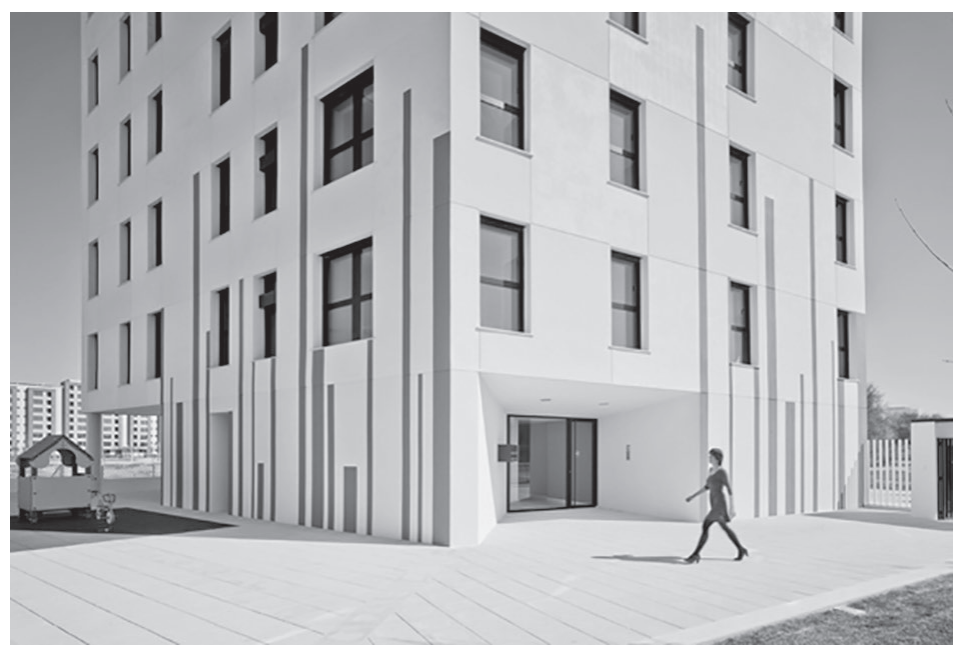

14. Rosana PÉREz GONZÁLEZ: Edificio en bloque aislado de 15 viviendas, Albacete, 2013. Vista exterior del portal.

(según el DRAE ${ }^{27}$, «que tiene buena educación o urbanidad»). Es amable por su escala, capaz de dar la réplica tanto a lo que la rodea como a las personas que la visitan y la habitan. Es amable por su simpatía, por esa suerte de frescura que desprende y por el aire de cierta ingenuidad.

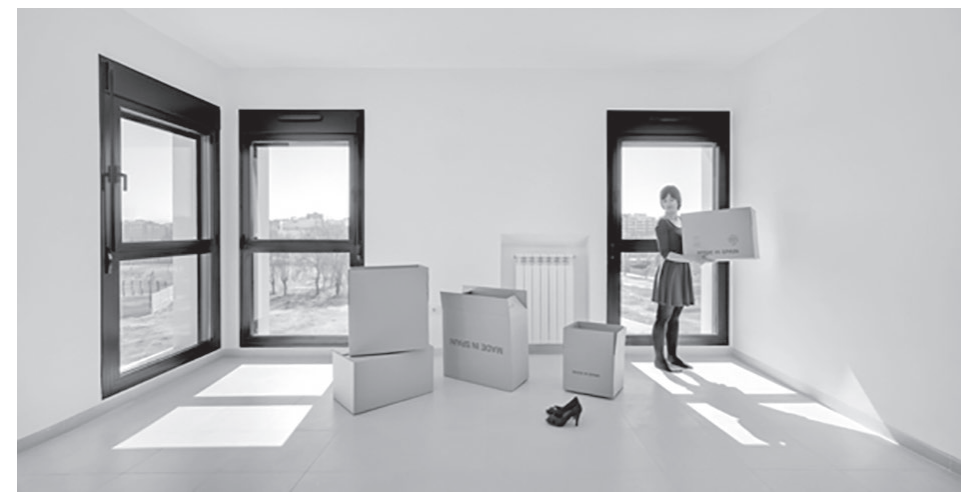

15. Rosana PÉrez GonZÁLEz: Edificio en bloque aislado de 15 viviendas, Albacete, 2013. Vista interior de una vivienda.

27. <http://lema.rae.es/drae/>, consultado el 07-02-2014

Feminismo/s 23, junio 2014, pp. 227-250 
Es también una arquitectura inteligible, clara, racional, luminosa por fuera y por dentro. Sencilla y con gracia a la vez. Cotidiana pero no vulgar, está hecha y pensada para vivirla, para disfrutarla, para transformarla sin que pase nada... para quitarse los zapatos, feliz, nada más llegar a casa, ja casa!

Es verdad que no es un proyecto brillante e intuimos que nunca quiso serlo. Los brillos deslumbran y ciegan y alejan y estas casas invitan a pasar y a quedarse, llaman a habitar.

Quedéme y olvidéme;

el rostro recliné sobre el amado;

cesó todo, y dejéme

dejando mi cuidado

entre las azucenas olvidado ${ }^{28}$.

No podría decir que esta arquitectura es así porque es obra de una mujer: sería mucho decir, aunque me gusta pensarlo. Pero sí creo que es así porque es atenta y está atenta: a su lugar (al fin y al cabo, una ciudad de provincias) y a su tiempo, los albores del siglo XXI que una película mítica soñaron como odisea del espacio ${ }^{29}$ (Stanley Kubrick, 1968). Está atenta a lo que pasa, a lo que está cambiando o claramente ya ha cambiado y trata de darle una respuesta. Quizá no es una respuesta sabia y magnífica, pero sí es lúdica, lo cual, según Schiller, va más allá del hacer y del pensar porque atiende y apunta a disfrutar.

Hay sencillez y alegría en estas casas: una sencillez no puritana ni censora, sino natural, y una alegría sin alboroto, como una sonrisa. Están pensadas y construidas para sentirse bien, para estar bien, cada uno y cada una en su piel y con los y las demás. Poco importa si se vive solo o en compañía, si se es niño o anciano, hombre o mujer, hetero, homo o transexual. Como recoge el $\mathrm{DRAE}^{30}$, que en su vigésimo tercera edición ha enmendado el artículo «familia», estas viviendas son para «personas relacionadas por amistad o trato», es decir, por el parentesco del afecto que llena de sentido la vida.

Es una arquitectura que celebra esa vida, la buena vida parafraseando a Ábalos: es una arquitectura para, en el buen sentido de la palabra, vividores y vividoras... un auténtico brote verde en medio los llanos amarillos de Albacete y bajo su intenso y limpio cielo azul.

28. SAN JUAN DE LA CRUZ (1542-1591). Noche oscura. Madrid, Editorial de Espiritualidad, 2003 ( $2^{\mathrm{a}}$ ed.)

29. Arnau Amo, Joaquín y GutiÉRrez Mozo, María Elia. «2012: una odisea urbana. La nueva sede de la Confederación de Empresarios de Albacete (FEDA)». Dearq 11 (2012), pp. 94-107.

30. <http://lema.rae.es/drae/>, consultado el 20-06-2014. 


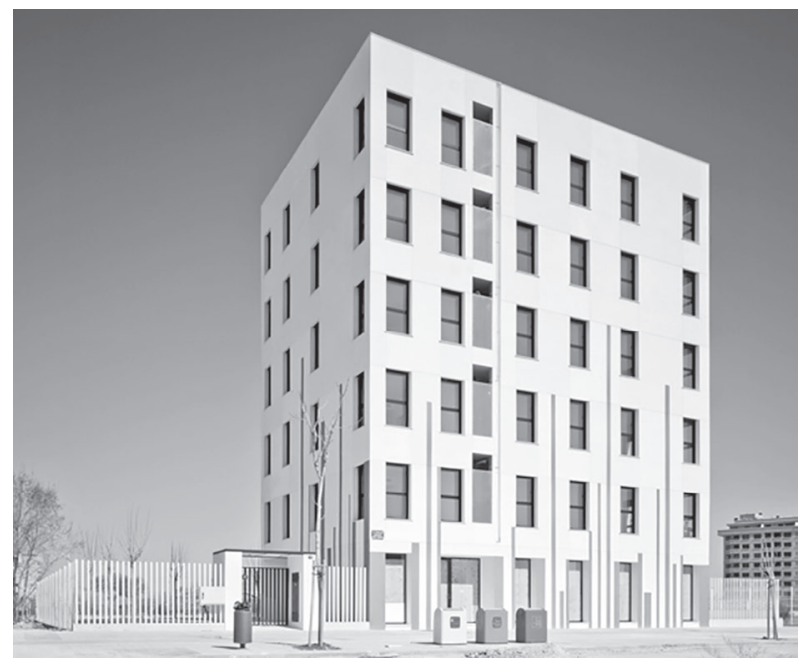

16. Rosana PÉREZ GonZÁlez: Edificio en bloque aislado de 15 viviendas, Albacete, 2013. Vista exterior.

\section{Referencias bibliográficas}

ÁBALOS, Iñaki. La buena vida: visita guiada a las casas de la modernidad. Barcelona, Gustavo Gili, 2001.

ARnAU Amo, Joaquín. 72 voces para un diccionario de arquitectura teórica. Madrid, Celeste, 2000.

ARnau Amo, Joaquín y et al. Palladio 1508-2008: una visión de la Antigüedad. Valencia, General de Ediciones de Arquitectura, 2009.

ARnAU AMO, Joaquín y GutiÉRREZ Mozo, María Elia. «2012: una odisea urbana.

La nueva sede de la Confederación de Empresarios de Albacete (FEDA)».

Dearq 11 (2012), pp. 94-107.

BORSI, Franco y PORTOGHESI, Paolo. Victor Horta. Bruselas, Marc Vokaer, 1970 CONSEJO SUPERIOR DE LOS COLEGIOS DE ARQUITECTOS DE ESPAÑA. Modos de habitar. Madrid, CSCAE, 2010.

Constant, Caroline et alt. Palladio. Barcelona, Gustavo Gili, 1988.

ESPEgel Alonso, Carmen. Heroínas del espacio: mujeres arquitectos en el movimiento moderno. Valencia, Ediciones Generales de la Construcción, 2006.

GANS, Deborah. Le Corbusier. Barcelona, Gustavo Gili, 1992.

GutiÉRREZ Mozo, María Elia. «Arquitectura y urbanismo con perspectiva de género». Feminismo/s 17 (2011).

- Arquitectura y Composición. Alicante, Editorial Club Universitario, 2013.

Hernández PeZzi, Carlos y Durán, María Ángeles. La ciudad compartida. Madrid, CSCAE, 1998. 
Huete Machado, Lola. «La tierra media». El País Semanal 1883 (2012).

KliczKowski Wladimirski, María Sol. Victor Horta. Madrid, A. Asppan, 2003.

LABORDA YNEVA, José. Enseñar arquitectura: lecciones de composición arquitectónica. Zaragoza, Institución Fernando el Católico, 2008.

Loos, Adolf. Ornamento y delito y otros escritos. Barcelona, Gustavo Gili, 1972.

MONTANER, Josep Maria y MuXí, Zaida. Habitar el presente: herramientas para la vivienda del siglo XXI. Barcelona, David Hernández Falagán, 2011.

Monteys RoIG, Xavier. Le Corbusier: obras y proyectos. Barcelona, Gustavo Gili, 2005.

Planelles, Mercedes (coord.). Nuevos modos de habitar. New ways of housing. Valencia, Colegio Oficial de Arquitectos de la Comunidad Valenciana, 1996.

SARQUIS, Jorge (comp.). Arquitectura y modos de habitar. Buenos Aires, Nobuko, 2006.

TUSQUETS, Óscar. Dios lo ve. Barcelona, Anagrama, 2001.

UrRUtia NúÑEZ, Ángel. Arquitectura española, siglo XX. Madrid, Cátedra, 1997. 